\title{
Comparative Study of Intravitreal Ranibizumab with and Without Nepafenac Eye Drops for Center Involving Diabetic Macular Edema
}

\author{
Authors \\ Mohsen Abou Shousha MD, Hany Ahmed Helaly MD \\ Ophthalmology Department, Faculty of Medicine, Alexandria University, Egypt
}

\begin{abstract}
Purpose: to compare intravitreal ranibizumab with and without Nepafenac eye drops as a treatment for center involving diabetic macular edema.

Methods: This is a randomized, comparative, double masked, interventional prospective clinical study that included 60 eyes with center involving diabetic macular edema and had good metabolic control, randomly assigned into 2 groups (A and B). Patients had monthly intra-vitreal injection of $0.5 \mathrm{mg}$ ranibizumab (Lucentis; Novartis, Basel, Switzerland and Genentech Inc., South San Francisco, CA) for the first three months. In the next nine months, reinjection was done according to predetermined reinjection criteria. Group B had in addition topical Nepafenac eye drops $0.1 \%$ (Nevanac; Alcon Labs, Fort Worth, TX, USA), three times daily for twelve months.

Results: As regards the mean central macular thickness (CMT) at 12 months, it was $320 \pm 63$ microns and $310 \pm 71$ microns for group $A$ and $B$ respectively $(p=0.311)$. The mean number of injections in the 12 months follow up period was $6.9 \pm 1.1$ (range from 5 to 9 ) and $5.9 \pm 1.18$ (range from 4 to 8 ) for group $A$ and group B respectively $(p=0.002)$.

Conclusion: Nepafenac $0.1 \%$ eye drops three times daily may be a good adjuvant to intravitreal ranibizumab in the treatment of diabetic macular edema that decrease the number of ranibizumab injections needed for those patients.

Keywords: Diabetic Macular Edema, Nepafenac, Ranibizumab, Lucentis; Intravitreal Injection.
\end{abstract}

\section{Introduction}

Diabetes Mellitus (DM) affects more than 220 million people worldwide. ${ }^{(1)}$ Diabetic macular edema (DME) is one of the major causes of visual impairment in patients with diabetic retinopathy (DR). ${ }^{(2,3)}$ With diabetes prevalence estimated to double during the next 20 years, ${ }^{(4)}$ in the future it is likely that DME may be responsible for substantial vision loss unless treated adequately.

The crude prevalence rate of DM in Egypt in 2008, was calculated to be $4.07 \%$. ${ }^{(5)}$ DR is the most common ocular complication of $\mathrm{DM},{ }^{(6)}$ and its prevalence is higher in type I diabetics than in those with type II disease. ${ }^{(7)} \mathrm{DR}$ is the third most common cause of blindness in the United States and the leading cause of new blindness in individuals 20-74 years of age. ${ }^{(8)}$ Macular edema is the major cause of visual loss in patients with DR. The incidence of DME after 10 years of follow-up has been reported to be higher in type II diabetes than in type I especially in insulin dependent type II diabetes. ${ }^{(9)}$ 
Ranibizumab (Lucentis; Novartis, Basel, Switzerland and Genentech Inc., South San Francisco, CA) is approved in many countries for four major indications: neovascular age-related macular degeneration, visual impairment due to DME, visual impairment secondary to macular edema in branch or central retinal vein occlusion, and visual impairment due to choroidal neovascularization secondary to pathologic myopia. ${ }^{(10,11)}$ Non-steroidal anti-inflammatory drugs (NSAIDs) are one of the most commonly prescribed classes of medications and are routinely employed for their analgesic, antipyretic, and anti-inflammatory properties. NSAIDs are potent inhibitors of cyclo-oxygenase (COXs) enzymes and thereby the synthesis of proinflammatory prostaglandins (PGs). In ophthalmology, topical NSAIDs are used to stabilize pupillary dilation during intraocular surgery and to treat allergic conjunctivitis and postoperative inflammation, pain and cystoid macular edema (CME). ${ }^{(12-17)}$ If an NSAID can penetrate to the retina, it could possibly reduce vascular permeability by inhibiting the inflammatory cascade. Based on this hypothesis, patients with DME may benefit from topical nepafenac $0.1 \%$ in an attempt to reduce the edema and improve vision.

The aim of this work was to compare intravitreal ranibizumab with and without nepafenac eye drops as a treatment for center involving diabetic macular edema.

\section{Subjects and Methods}

This is a randomized, comparative, double masked, interventional prospective clinical trial that included 60 eyes with center involving diabetic macular edema, randomly assigned into 2 groups. Group A: included 30 eyes that had good metabolic control as regards the blood glucose level guided by glycosylated hemoglobin level (HbA1c), serum cholesterol and triglyceride level, renal function, and blood pressure. Those patients had monthly intra-vitreal injection of $0.5 \mathrm{mg}$ ranibizumab (Lucentis; Novartis, Basel, Switzerland and Genentech Inc., South San Francisco, CA) for the first three months. In the next nine months, reinjection was done according to the retreatment criteria mentioned below. In addition, patients received placebo eye drops three times daily for 12 months. Group B: included30 eyes that had the same previously mentioned measures in addition to topical Nepafenac eye drops $0.1 \%$ (Nevanac; Alcon Labs, Fort Worth, TX, USA), three times daily for 12 months.

The inclusion criteria were as follows: Eyes with central foveal cyst proved by optical coherence tomography (OCT) regardless the central macular thickness or eyes with clinically significant diabetic macular edema proved to be center involving by OCT. The cut-off values for retinal thickening were taken as the mean plus two standard deviations of normal subjects examined with the same OCT machine (Cirrus SD-OCT, software version 3.0; Carl Zeiss Meditec, Inc.) in a previous study (figure 1). ${ }^{(18)}$

All included eyes were subjected to full ophthalmic examination at initial visit and monthly for twelve months as regards: best spectacle corrected visual acuity (BSCVA), detailed slit-lamp anterior segment examination, intraocular pressure using applanation tonometry, and dilated fundus examination using noncontact slit-lamp biomicroscopy. Color fundus photography and fluorescein angiography was done at the initial visit.OCT Cirrus (SD-OCT, software version 6.0; Carl Zeiss Meditec, Inc.) was done at initial visit and monthly for twelve months.

After the first 3 months, monthly injection was continued if stable visual acuity and OCT were not reached. Injection was suspended after the first 3 months if there were no further BSCVA improvement attributable to treatment with intravitreal injection at the last 2 consecutive visits proved by OCT. After suspension, injections was to be resumed pro re nata (PRN) as required if there was a decrease in BCVA due to DME progression, confirmed by clinical evaluation and OCT. Whether the patients received or did not receive nepafenac eye drops was blinded from both the patient and the clinician.

Eyes with one or more of the following criteria were excluded: center non-involving macular edema proved by OCT (central macular thickness (CMT) equal to or less than 303 microns), vitreomacular traction proved 
by OCT, other pathologies like venous occlusions or chronic uveitis, anterior segment surgeries within one year, history of posterior segment surgeries within the last 6 months, history of intra-vitreal injections within the last 6 months, history of macular laser therapy within the last 6 months, and media opacities preventing clinical examination or proper OCT segmentation.

All included patients signed an informed consent. This study was approved by the local research committee of Faculty of Medicine, Alexandria University, Egypt. The tenets of Declaration of Helsinki were followed. The primary outcome was the change in BSCVA.

Clinical findings were statistically evaluated using Excel 2007 (Microsoft Corp.) and SPSS software version 15.0 (SPSS Inc, Chicago, IL). Means and standard deviations were calculated. To check for normal distribution, the Kolmogorov-Smirnov test was applied. Comparisons of the means of normally distributed data were performed with the $\mathrm{t}$ test. A $P$ value less than 0.05 was considered statistically significant.

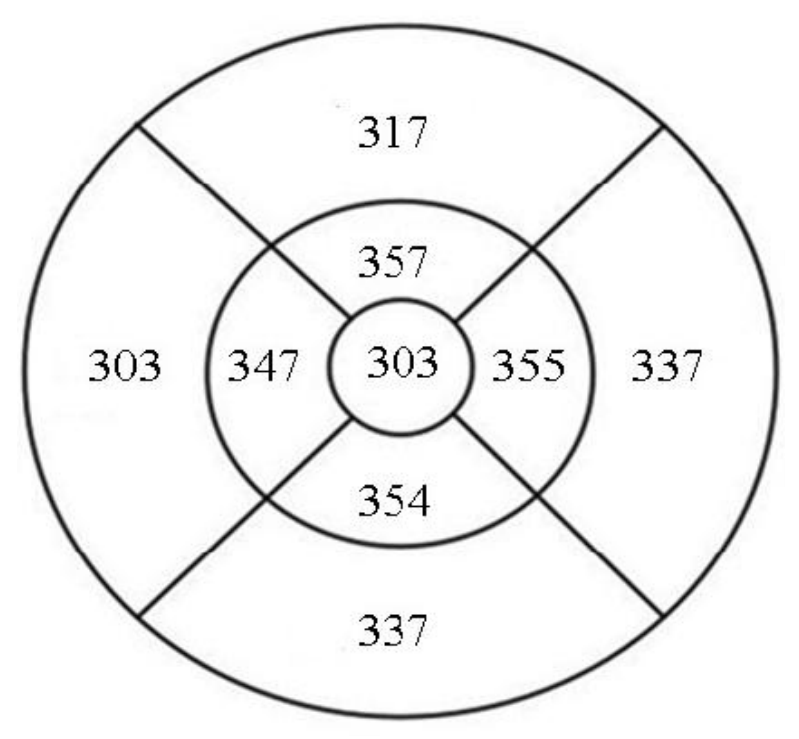

Figure 1:Cut-off values for retinal thickening were taken as the mean plus two standard deviations of normal subjects examined with the same OCT machine. ${ }^{(18)}$

\section{Results}

The study included 60 eyes. Group A included 30 eyes (19 right and 11 left eyes). The mean age was $57.5 \pm$ 6.4 years. There were 21 males and 9 females. Group B included 30 eyes (17 right and 13 left eyes). The mean age was $55.5 \pm 6.7$ years. There were 18 males and 12 females. There was no statistically significant difference between the two groups as regards the age and sex distribution ( $p>0.05)$.

As regards the central macular thickness (CMT), group A had mean CMT of $427 \pm 88$ microns at baseline, $340 \pm 78$ microns at 3 months, $350 \pm 77$ microns at 6 months, and $320 \pm 63$ microns at 12 months. Group B had mean CMT of $435 \pm 83$ microns at baseline, $350 \pm 90$ microns at 3 months, $342 \pm 74$ microns at 6 months, and $310 \pm 71$ microns at 12 months (figure 2). There was no statistically significant difference between the 2 groups at baseline $(\mathrm{p}=0.251)$ and at 12 months $(\mathrm{p}=0.311)$. Both groups showed statistically significant decrease in CMT from the baseline levels at 12 months $(\mathrm{p}<0.001)$.

As regards BSCVA, group A had mean BSCVA of 0.61 and $0.27 \operatorname{logMAR}$ at baseline and 12 months respectively. Group B had mean BSCVA of 0.65 and $0.25 \operatorname{logMAR}$ at baseline and 12 months respectively (figure 3). There was no statistically significant difference between the 2 groups at baseline $(p=0.41)$ and at 12 months $(\mathrm{p}=0.33)$. Both groups showed statistically significant improvement in BSCVA from the baseline levels at 12 months $(\mathrm{p}<0.001)$. 
Both groups had monthly injection for 3 months then PRN. The mean number of injections in the 12 months follow up period was $6.9 \pm 1.1$ (range from 5 to 9) and $5.9 \pm 1.18$ (range from 4 to 8 ) for group A and group $B$ respectively. Using $t$ test, there was a statistically significant difference between the two groups $(t=3.267$, $\mathrm{p}=0.002)$.

Qualitative assessment of the OCT findings at baseline and at 12 months was done and classified as stable, better, or worse. For group A, 15 eyes were stable; 12 eyes were better; and 3 eyes were worse. For group B, 13 eyes were stable; 16 eyes were better; and one eye was worse. This was not statistically significant $(\mathrm{p}=$ $0.424)$.

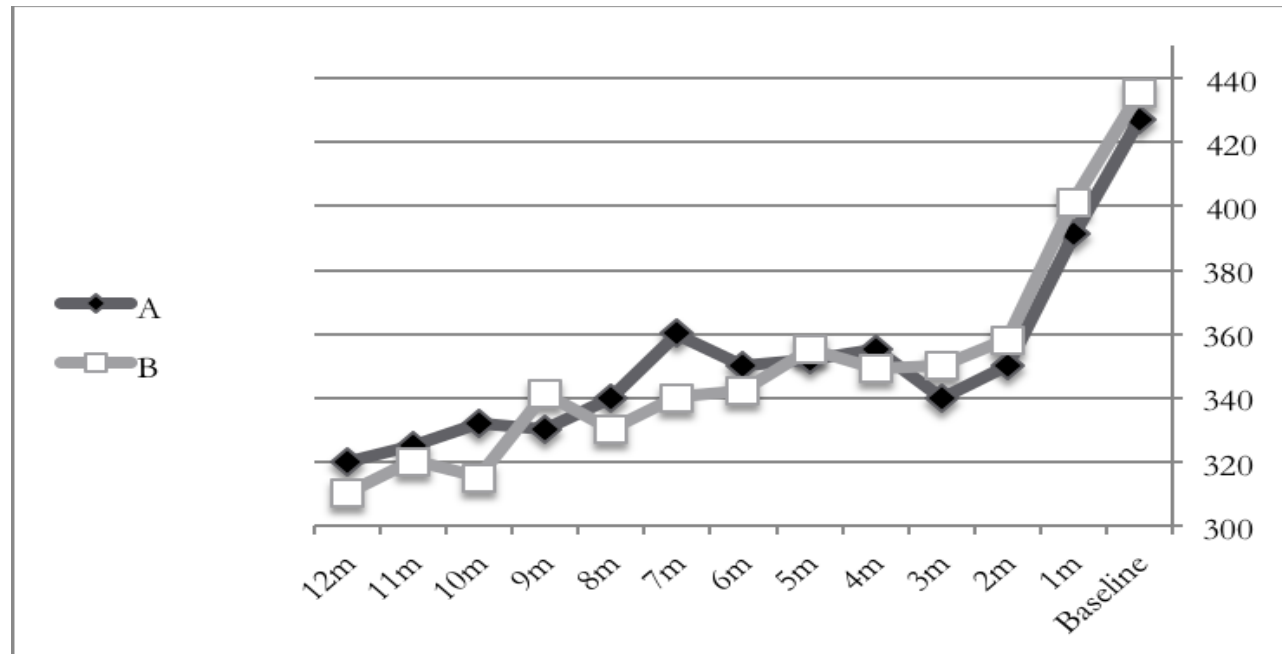

Figure 2: Central macular thickness (CMT) of the two groups (group A: Ranibizumab alone and group B: Ranibizumab with Nepafenac eye drops) along the 12 months of follow up.

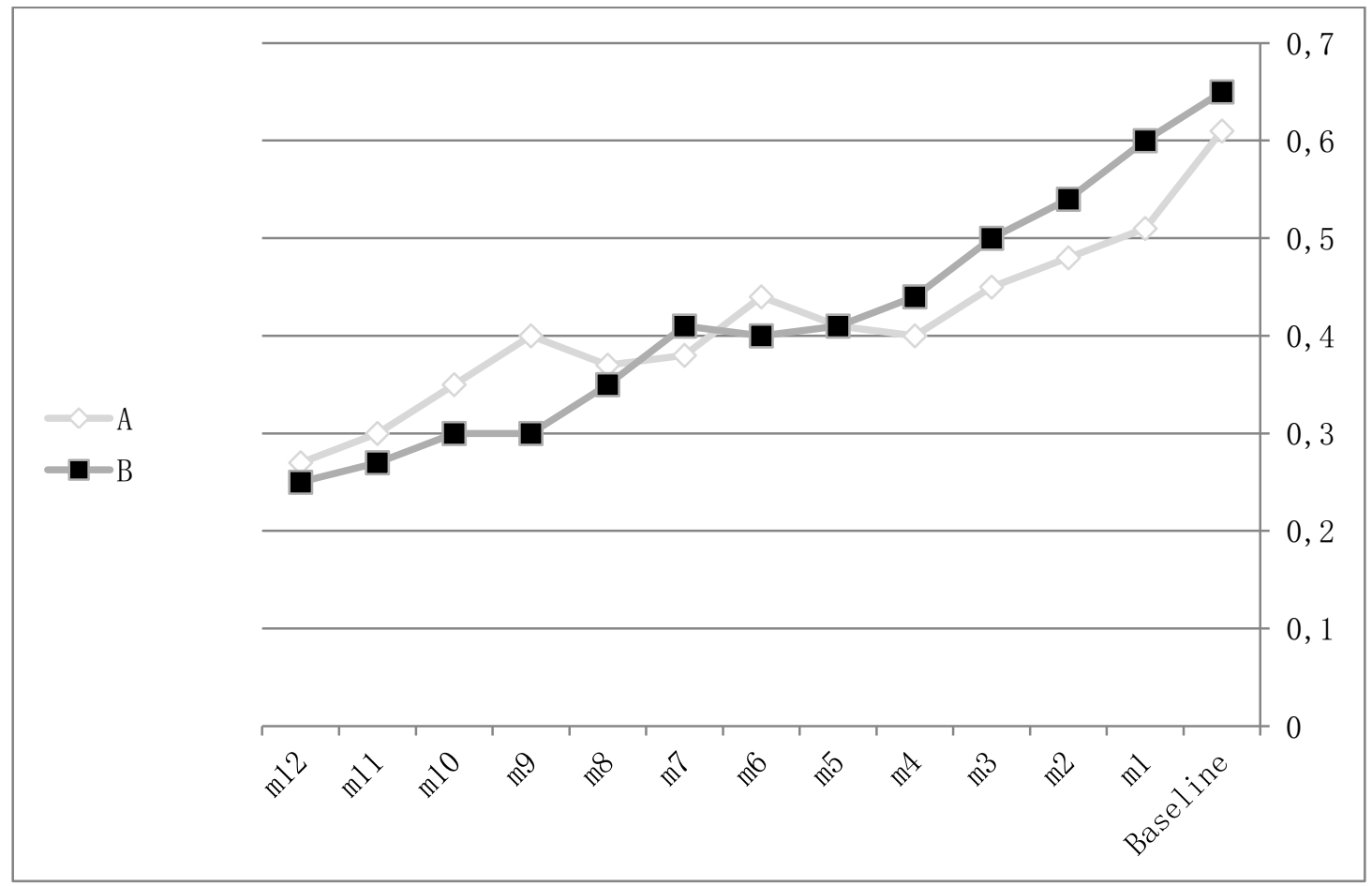

Figure 3: Best spectacle corrected visual acuity (BSCVA) (logMAR) of the two groups (group A: Ranibizumab alone and group B: Ranibizumab with Nepafenac eye drops) along the 12 months of follow up. 


\section{Discussion}

Nepafenac is a nonsteroidal anti-inflammatory prodrug approved for the treatment of postcataract surgery pain and inflammation. It has superior corneal penetration compared to other NSAIDs and is bio activated by ocular tissues to amfenac. ${ }^{(13,19)}$

Several studies have measured aqueous levels of NSAIDs in humans after topical use. After a single application, peak aqueous drug levels are detectable for nepafenac $0.1 \%(205.3 \mathrm{ng} / \mathrm{mL}$; peak 30 minutes $) .{ }^{(13)}$ In contrast to aqueous drug levels, there is a paucity of human studies measuring NSAID levels in the vitreous after topical application. A single study measured vitreous drug levels in patients who received ketorolac $0.4 \%$ four times daily, bromfenac $0.09 \%$ two times daily, or nepafenac $0.1 \%$ three times daily for three days before vitrectomy surgery. Vitreous levels of ketorolac, bromfenac, and amfenac were reported as $2.8 \mathrm{ng} / \mathrm{mL}, 0.96 \mathrm{ng} / \mathrm{mL}$, and $2.0 \mathrm{ng} / \mathrm{mL}$, respectively. Therefore both bromfenac and amfenac may be more beneficial in the treatment of DME compared to ketorolac due to their higher levels of posterior segment penetration. Aqueous and vitreous concentrations of NSAID would likely have a direct effect on anterior (ciliary body and iris) and posterior (retina and choroid) PG production, respectively. ${ }^{(14)}$

Elbendary and Shahin ${ }^{(15)}$ compared intravitreal diclofenac $(500 \mathrm{mcg} / 0.1 \mathrm{~mL})$ to intravitreal triamcinolone $(4 \mathrm{mg} / 0.1 \mathrm{~mL})$ in the treatment of diffuse DME in a randomized study. Central macular thickness (CMT) decreased in the diclofenac group from 419.8 microns at baseline to 323.5 microns at one month and 271.1 microns at three months. There was no difference between the two groups in CMT, final visual acuity (VA), mean line improvement, and percent of eyes with improved VA.

In a small consecutive case series ( 6 eyes) reporting the effect of topical nepafenac $0.1 \%$ monotherapy twice daily for an average of 210 days on DME, the VA improved significantly from a mean of $0.78 \log$ MAR to a mean of $0.67 \log$ MAR at the end of study. Also the CMT decreased significantly from a mean of 417 microns to a mean of 267 at the end of the study. ${ }^{(16)}$

In a study on diabetic rats, Kern et al. ${ }^{(17)}$ concluded that topical administration of drugs via eye drops is a desirable route of delivery to the retina, since it minimizes the potential systemic side effects. Nepafenac administered via eye drops reaches the retina of rats in sufficient concentration to inhibit multiple biochemical and morphologic abnormalities in diabetes. Nepafenac has also had significant beneficial effects in other ocular pathologies, including ocular trauma and retinal and choroidal neovascularization. Appreciable evidence shows that systemic inhibition of COXs and their PG products can inhibit metabolic, physiologic, and histologic abnormalities characteristic of the early stages of DR. Inhibition of early functional and morphologic abnormalities of diabetes by topical Nepafenac offers a novel therapeutic approach toward inhibiting the development of DR.

The 3-years results of the RESTORE extension study confirmed the favorable efficacy and safety profiles of ranibizumab in the long-term treatment of visual impairment due to DME. Ranibizumab treatment was generally well tolerated, and there were no new ocular or systemic adverse effects. The safety profile of ranibizumab observed in the RESTORE extension study is consistent with the well-established safety profile of ranibizumab. ${ }^{(11)}$

In the current study, both groups had no significant difference at baseline as regards the age and sex distribution, mean BSCVA, and mean CMT. Both groups had significant reduction in mean CMT and improvement in mean BSCVA from baseline at 12 months. Group B receiving nepafenac eye drops showed slightly better final CMT and BSCVA at 12 months. However, there was no statistically significant difference.

Patients receiving nepafenac eye drops had statistically significant less number of injections during the 12 months follow up. As regards qualitative assessment of OCT findings, group B receiving nepafenac eye 
drops showed slightly better outcome but this was not statistically significant. More number of patients may be needed to get significant results.

In conclusion, Nepafenac $0.1 \%$ eye drops three times daily may be a good adjuvant to intravitreal ranibizumab in the treatment of diabetic macular edema that decrease the number of ranibizumab injections needed for those patients.

\section{Acknowledgment: none}

Financial interest: none

\section{References}

1. Diabetes fact sheet No. 312 [article online 2009]. Available from: http://www.who.int/mediacentre/factsheets/fs312/en/ Accessed 20 December 2009.

2. Resnikoff S, Pascolini D, Etya'ale D, et al. Global data on visual impairment in the year 2002. Bull World Health Organ 2004; 82:844-51.

3. Klein R, Klein BE, Moss SE, et al. The Wisconsin Epidemiologic Study of Diabetic Retinopathy: XVII. The 14-year incidence and progression of diabetic retinopathy and associated risk factors in type 1 diabetes. Ophthalmology 1998;105:1801-15.

4. King H, Aubert RE, Herman WH. Global burden of diabetes, 1995-2025: prevalence, numerical estimates, and projections. Diabetes Care 1998;21:1414-31.

5. Ahmed N, Arafa S, Amin G. The Epidemiology of Diabetes Mellitus in Egypt : Results of a National Survey. The Egypt J Community Med 2010; 28:29-43.

6. Roy MS, Klein R, O'Colmain BJ, et al. The Prevalence of diabetic retinopathy among Adult Type 1 Diabetic Persons in the U.S.A. Arch Ophthalmol 2004; 122:546-51.

7. Cahill M, Halley A, Codd M, et al. Prevalence of diabetic retinopathy in patients with diabetes mellitus diagnosed after the age of 70 years. Br J Ophthalmol 1997; 81:218-22.

8. Brown JB, Pedula KL, Summers KH. Diabetic retinopathy: Contemporary prevalence in a wellcontrolled population. Diabetes Care 2003;26:2637-42.

9. Klein R, Klein BEK, Moss SE, Cruickshanks KJ. The Wisconsin Epidemiologic Study of Diabetic Retinopathy: XV. The long-term incidence of macular edema. Ophthalmology 1995; 102:7-16.

10. Lucentis, Summary of product characteristics. Section 4.1 Therapeutic indications. 2013. Available at: http://www.ema.europa.eu/ docs/en_GB/document_library/EPARProduct_Information/human/000715/WC500043546.pdf. Accessed November 24,2013.

11. Schmidt-Erfurth U, Lang GE, Holz FG, et al. Three-Year Outcomes of Individualized Ranibizumab Treatment in Patients with Diabetic Macular Edema.The RESTORE Extension Study. Ophthalmology 2014; 121(5): 1045-53.

12. Kim SJ, Flach AJ, and Jampol LM. Nonsteroidal anti-inflammatory drugs in ophthalmology. SurvOphthalmol 2010; 55(2):108-33.

13. Walters T, Raizman M, Ernest P, et al. In vivo pharmacokinetics and in vitro pharmacodynamics of nepafenac, amfenac, ketorolac, and bromfenac. J Cataract Refract Surg 2007; 33(9): 1539-45.

14. Heier JS, Awh CC, Busbee BG, et al. Vitreous non-steroidal anti-inflammatory drug concentrations and prostaglandin E2 levels in vitrectomy patients treated with ketorolac $0.4 \%$, bromfenac $0.09 \%$, and nepafenac 0.1\%. Retina 2009; 29 (9): 1310-3.

15. Elbendary AM and Shahin MM. Intravitreal diclofenac versus intravitreal triamcinolone acetonide in the treatment of diabetic macular edema. Retina 2011; 31(10): 2058-64. 
16. Callanan D, Williams P. Topical nepafenac in the treatment of diabetic macular edema. ClinOphthalmol 2008; 2(4): 689-2.

17. Kern TS, Miller CM, Du Y, et al. Topical Administration of Nepafenac Inhibits Diabetes-Induced Retinal Microvascular Disease and Underlying Abnormalities of Retinal Metabolism and Physiology. Diabetes 2007; 56:373-9.

18. AbouShousha MA, Sabry HN. Retinal Measurements: Comparison Between Spectral Domain and Time Domain Optical Coherence Tomography. Delta J Ophthalmol 2009; 10:91-5.

19. Lindstrom R, Kim T. Ocular permeation and inhibition of retinal inflammation: an examination of data and expert opinion on the clinical utility of nepafenac. Curr Med Res Opin. 2006;22(2):397404.

\section{List of abbreviations:}

Diabetes Mellitus (DM)

Diabetic macular edema (DME)

diabetic retinopathy (DR)

Non-steroidal anti-inflammatory drugs (NSAIDs)

prostaglandins (PGs)

cystoid macular edema (CME)

optical coherence tomography (OCT)

pro re nata $(\mathrm{PRN})$ 